\title{
Fostering Student Success in the Campus Community
}

\author{
by Gary L. Kramer and Associates
}

Published by Jossey-Bass, 2007, 460 pages

\section{Reviewed by}

Brian M. Orefice (borefice@miami.edu), Director of Orientation and Adjunct Faculty, School of Education, University of Miami

New student orientation is a unique event in that it involves the entire campus community. Professionals who are responsible for orientation, transition, and retention understand that a successful undergraduate experience is often contingent upon the creation of a "student-centered" campus infrastructure. Gary Kramer and Associates' Fostering Student Success in the Campus Community is fundamentally about building campus partnerships - a practice that those involved in the coordination of new student orientation programs must master, given the nature of our work.

As institutions build partnerships between key institutional playerspolicymakers, administration, faculty, service providers, students, and the educational community at large-a culture of student success will grow. Realizing that the interpretation of student success may vary among diverse institutions of higher education, the authors offer no standard definition. They do assert, however, that "student learning, growth and success" is the responsibility of everyone on campus (p. xxxiii). Similar to the development of a comprehensive new student orientation program in both theory and practice, involving the campus community in this strategic and systematic endeavor is essential.

Although there are over 20 chapters, this volume has been organized into four themed parts, each containing five chapters. Part I, "Communicating Expectations," opens with valuable information about current student demographic trends. The remaining four chapters in Part I focus on creating a student-centered culture, which often requires the alignment of institutional practices and expectations. Special attention is given to the role that program assessment plays within the development of student services. Taken together, the chapters within this first part of the book include various models and institutional practices that have been designed to facilitate student success.

The first chapter, "Knowing Today's and Tomorrow's Students" by Vasti Torres, challenges student affairs professionals to create campus environments that support multiple types of students. Torres discusses the advancement of technology and its impact on college students. We are aware that new students use online social networking sites such as Facebook to connect with each other- 
oftentimes in advance of their orientation program. Institutions can and should use these online social networks as a vehicle for the dissemination of information to new students. For example, orientation programs can create department pages within Facebook and invite new students to join so that they can receive updates and information, meet new students, or ask questions.

Torres also provides information about changing student demographics, and how factors such as gender, race/ethnicity, and age can impact student access and persistence. Though most orientation programs include sessions about multiculturalism and diversity, it is important for underrepresented students to have opportunities to connect with each other. Institutions that provide such opportunities within or beyond orientation-such as through pre-orientation programs or first-year seminars for special populations-may best serve the needs of these oftentimes marginalized students. Overall, Torres uses Chapter 1 to provide context for the discussion of student success and establishes the foundation upon which the remaining chapters in this book are built.

Part II, "Connecting Services," details various strategies that can be implemented to organize campus services in a way that creates an integrated learning environment for students. Though a significant portion of this part of the book is dedicated to academic and career advising services, Chapter 7, "Connecting One-Stop Student Services" by Louise Lonabocker and J. James Wager, is particularly salient to the work of the orientation professional. This chapter challenges readers to think about their campus services from the student perspective and encourages us to consider both their physical and virtual organization. The authors of this chapter provide specific examples from institutions that have consolidated the physical location of related student services, such as residential and dining services, orientation, financial aid, and the registrar. While institutions may vary on the physical location of their department of orientation, it remains consistent that orientation provides new students with comprehensive information about the institution.

Regardless of their physical location on campus, orientation staff members often have the responsibility for bringing these services together in the virtual world. Chapter 7 provides some concrete examples of institutional practices in regard to the use of technology which can be easily adapted for orientation purposes. Beyond the virtual world, orientation professionals have to be mindful of the accessibility of these campus services when new students arrive on campus. New students will need to be guided to these services, whether or not they are consolidated into a one-stop location. There is an interrelationship between service and technology, and integration of the two often provides the best "customer service" for our constituents.

Part III, "Fostering Student Development," combines several psychosocial development theories in order to advocate for a holistic approach to student success. The chapters within this part of the book suggest that creating learning partnerships across the institution will encourage students to take ownership over their learning, best preparing them to become autonomous adults. Chapter 14, "Preparing Service Providers to Foster Student Success" by Tom Brown and Lee 
Ward, offers specific advice to student service professionals who seek institutional collaboration in order to provide comprehensive services to students. The authors focus on the importance of out-of-the-classroom learning and discuss ways in which the campus community can come together to facilitate student success.

Recommendations are drawn in large part from the results of the Documenting Effective Educational Practice (DEEP) project by George Kuh in Student Success in College: Creating Conditions That Matter (2005). The DEEP report indicates that it is important to have the "right people doing the right things" in order to create campus environments that will prioritize student success and development (Kuh, Kinzie, Schuh, Whitt, \& Associates, 2005, p. 309). Specific recommendations for training and preparation programs that can be used for what the authors term as "administrative" and "instructional" faculty are included. Though it stands to reason that most orientation professionals would be considered administrative faculty by definition, both administrative and instructional faculty from across the institution are involved with the development of the orientation program. To contribute to the overall effectiveness of the orientation planning team, several of the authors' suggestions for training and preparation could be applied. For example, a pre-service and in-service development program that focuses on the content, audience, and techniques involved with the implementation of an orientation program could be incorporated into the process.

The final section of this book, Part IV, "Achieving Success," highlights best practices, reinforces the book's themes with regard to specific student populations, and reemphasizes the importance of identifying the conditions needed to facilitate student success. Specifically, Chapter 17, "Achieving Student Success in the First Year of College" by Randy Swing and Tracy Skipper, provides a wealth of information that is relevant to those working with orientation, transition, and retention. Their chapter is based on proven educational research that relates to the unique challenges students encounter in their first year of college.

The authors discuss four "lenses" that can be used to explore student success in the campus community. The first lens suggests that focusing on entering student characteristics can provide insight into why students might underperform or overperform in their first year. Though not always easy to correlate, factors such as academic preparation, socioeconomics, and firstgeneration status often require supplemental initiatives within the general orientation program. A second lens focuses on external influences, both national and regional. Events such as the recent economic downturn might have financial implications for the student and their family. Students could be more sensitive to fees that are incurred outside of their tuition bill, which often includes the costs of attending a summer orientation program (registration, travel, accommodations). A third lens focuses on what students do and how they spend their time in- and out-of-the-classroom. The new student orientation program introduces students to the campus climate and defines institutional expectations regarding student engagement. Finally, the fourth lens highlights what the institution does to facilitate student success, which is arguably the area in which the institution has the most control. For that reason, the authors focus the remainder of Chapter 17 
on the following four areas of institutional effort or control: values and goals, organizing structures, undergraduate teaching, and cocurricular experiences.

As the authors expand upon these four areas of institutional effort, they provide a substantial amount of information that orientation professionals will find relevant to their work. Swing and Skipper also outline how to construct a philosophy statement to guide first-year student services, including various organizational structures that institutions can use to deliver these services. In sum, this chapter masterfully organizes information about what institutions can do to foster first-year student success and how orientation professionals can participate in these efforts.

In many ways, this book could have been written and organized for orientation professionals. Kramer and associates intended for their volume to be utilized by those within the institution who have an understanding of the types of students who enroll and how they progress through the enrollment process. Beyond the institutional leaders and practitioners who are directly responsible for student services, anyone in the campus community concerned with student development, learning outcomes, shared partnerships, and student culture would benefit from reading this book. The authors offer the right combination of theory and research that institutions can use to implement effective practices that put "students first" within the campus community.

\section{Reference}

Kuh, G. D., Kinzie, J., Schuh, J. H., Whitt, E. J., \& Associates (2005). Student success in college: Creating conditions that matter. San Francisco: Jossey-Bass. 